\title{
A Novel Narrative E-Writing Intervention (NeW-I) for Parents of Children with Chronic Life-Threatening Illnesses: Protocol for an Open-Label Randomized Controlled Trial
}

Andy Hau Yan Ho ( $\sim$ andyhyho@ntu.edu.sg )

https://orcid.org/0000-0003-0373-7043

Oindrila Dutta

Nanyang Technological University https://orcid.org/0000-0002-2925-2477

Geraldine Tan-Ho

Nanyang Technological University

Toh Hsiang Benny Tan

Nanyang Technological University

Casuarine Low Xinyi

Nanyang Technological University

Sashikumar Ganapathy

Club Rainbow Singapore

Lee Beng Ang

KK Women's and Children's Hospital

Josip Car

Nanyang Technological University

Ringo Moon-Ho Ho

Nanyang Technological University

Chun Yan Miao

Nanyang Technological University

Study protocol

Keywords: Narrative Therapy, Psychotherapy, Pediatric Palliative Care, End-of-Life Care, Randomized Controlled Trial, Cyber-Counselling

Posted Date: November 28th, 2019

DOI: https://doi.org/10.21203/rs.2.12263/v3 
License: (c) (i) This work is licensed under a Creative Commons Attribution 4.0 International License. Read Full License 
The authors have withdrawn this preprint from Research Square 